\title{
АНАЛИЗ НОРМАТИВНЫХ ПРАВОВЫХ ДОКУМЕНТОВ, РЕГЛАМЕНТИРУЮЩИХ ОТКРЫТОСТЬ И ПРОЗРАЧНОСТЬ УПРАВЛЕНИЯ ОБЩЕСТВЕННЫМИ ФИНАНСАМИ В РОССИИ И ЗА РУБЕЖОМ
}

\begin{abstract}
Аннотация. Целью настоящей статьи является выявление соответствия российского законодательства и нормативного правового обеспечения положениям международных документов, регламентирующих открытость и прозрачность управления общественными финансами. В результате проведенного анализа выявлены положения российского законодательства не достаточно четко регламентирующие обеспечение открытости и прозрачности управления общественными финансами. Это позволило предложить соответствующие уточнения и рекомендации, позволяющие повысить доступность информации о финансовых операциях органов государственной власти и местного самоуправления для представителей гражданского общества. В настоящей статье был использован системный подход, мыслительно-логический метод, сравнительный анализ, индукция и дедукция. Полученные в ходе исследования выводы и аналитические материалы, характеризующие качество правового обеспечения открытости и прозрачности управления общественными финансами в Российской Федерации, могут быть использованы в целях повышения индекса открытости бюджета, рассчитываемого Международным бюджетным партнерством; активизации взаимодействия государства с институтами гражданского общества; обеспечения прозрачности и открытости информации о деятельности публично-правовых образований в сфере управления общественными финансами.

Ключевые слова: открытость, общественные финансы, прозрачность, государственный сектор, законодательство, гражданское общество, налогово-бюджетная срера, доступность, качество информации, надежность.

Review: The aim of the article is to reveal the compliance of Russian legislation and normative legal acts with the provisions of international documents regulating the openness and transparency of public finances management. On the base of the analysis the author reveals the provisions of Russian legislation which regulate the provision of the openness and transparency of public finances not clearly enough. The author offers certain specifications and recommendations which can raise the accessibility of information about financial operations of public and local authorities for the representatives of civil society. The author uses the systems approach, the logic method, the comparative analysis, induction and deduction. The conclusions and analytical materials of the research, characterizing the quality of legal provision of openness and transparency of public finances management in the Russian Federation, can be used for the purpose of raising of the budget openness index, calculated by the International Budget Partnership; activation of interaction between the state and civil society institutions; provision of openness and transparency of information about the activities of public institutions in the sphere of public finances management.
\end{abstract}

Keywords: quality of information, availability, fiscal area, civil society, legislation, government sector, transparency, public finances, openness, reliability.

$\Gamma$ лобальная инициатива по обеспечению открытости и прозрачности в налогово-бюджетной сфере возникла с конца 1990 годов после Азиатского кризиса, который выдвинул на первый план слабые стороны управления общественными финансами и риски, связанные с отсутствием раскрытия информации различным группам заинтересованных пользователей.

В этой связи МВФ был разработан Кодекс прозрачности в бюджетно-налоговой сфере; ОЭСР лучшие практики для бюджетной прозрачности;
МВФ - Руководство по статистике государственных финансов; ООН - Система национальных счетов и др. (таблица 1).

Несмотря на то, что перечисленные документы не имеют статус законодательных или нормативно правовых, они используются в качестве образцов лучшей практики и служат ориентиром обеспечения открытости и прозрачности управления общественными финансами в мировом масштабе.

Основным документом, регламентирующим открытость и прозрачность управления обще- 
Основные документы, регулирующие стандарты и принципы управления общественными финансами в зарубежной практике

\begin{tabular}{|c|c|c|c|c|}
\hline № & Название документа & Разработчик & Характеристика & Источник \\
\hline 1. & $\begin{array}{l}\text { Кодекс надлежащей } \\
\text { практики по обеспе- } \\
\text { чению прозрачности } \\
\text { в бюджетно-налого- } \\
\text { вой сфере }\end{array}$ & $\begin{array}{l}\text { МВФ, допол- } \\
\text { нен в } 2013\end{array}$ & $\begin{array}{l}\text { Качество и надежность опубликованной } \\
\text { информации; принципы и практики про- } \\
\text { зрачности в бюджетно-налоговой сфере; } \\
\text { набор ориентиров к полному соответ- } \\
\text { ствию международным стандартам }\end{array}$ & $\begin{array}{l}\text { http://www.pempal.org/data/ } \\
\text { upload/files/2014/06/cross_- } \\
\text { day-1_8_hughes_imf-new- } \\
\text { fiscal-transparency-code_rus. } \\
\text { pdf }\end{array}$ \\
\hline 2. & $\begin{array}{l}\text { Индекс открытости } \\
\text { бюджета (OBI) }\end{array}$ & МБП & $\begin{array}{l}\text { Всеобъемлющий анализ и обзор по оценке } \\
\text { степени предоставления центральными } \\
\text { правительствами стран всего мира досту- } \\
\text { па общественности к информации о бюд- } \\
\text { жете, а также возможностей участия в про- } \\
\text { цессе ведения бюджета }\end{array}$ & http://internationalbudget.org \\
\hline 3. & $\begin{array}{l}\text { Статистика государ- } \\
\text { ственных финансов } \\
\text { (GFSM 2014) }\end{array}$ & МВФ & $\begin{array}{l}\text { Стандарты для составления и предостав- } \\
\text { ления налогово-бюджетной статистики, } \\
\text { способствующие повышению качества } \\
\text { учета органов государственного управле- } \\
\text { ния и прозрачности операций }\end{array}$ & $\begin{array}{l}\text { http://www.imf.org/external/ } \\
\text { np/sta/gfsm/pdf/text14.pdf }\end{array}$ \\
\hline 4. & $\begin{array}{l}\text { Оптимальная прак- } \\
\text { тика по обеспече- } \\
\text { нию прозрачности } \\
\text { бюджета }\end{array}$ & ОЭСР & $\begin{array}{l}\text { Рекомендации в отношении основных до- } \\
\text { кументов бюджетной отчетности, каче- } \\
\text { ства и достоверности предоставляемых } \\
\text { данных }\end{array}$ & $\begin{array}{l}\text { http://www.oecd.org/ } \\
\text { governance/budgeting/ } \\
\text { Best } \% 20 \text { Practices\%20 } \\
\text { Budget } \% 20 \text { Transparency } \% 20 \\
\text {-\%20complete\%20with\%20 } \\
\text { cover\%20page.pdf. } \\
\end{array}$ \\
\hline 5. & $\begin{array}{l}\text { Система националь- } \\
\text { ных счетов }\end{array}$ & $\mathrm{OOH}$ & $\begin{array}{l}\text { Комплекс счетов, используемый для раз- } \\
\text { работки политики, анализа и научных ис- } \\
\text { следований. Первооснова для стандартов в } \\
\text { других областях экономической статистики }\end{array}$ & $\begin{array}{l}\text { http://unstats.un.org/unsd/ } \\
\text { nationalaccount/docs/ } \\
\text { SNA2008Russian.pdf }\end{array}$ \\
\hline
\end{tabular}

ственными финансами международного уровня, является Кодекс прозрачности в бюджетно-налоговой сфере (далее по тексту - Кодекс). За счет неукоснительного следования нормам Кодекса достигается прозрачность в управлении общественными финансами в развитых странах [1].

В соответствии с новыми положениями Кодекса, пересмотренного в 2014 году [2], акцент делается не столько на ясности предоставляемой информации, четкости юридических, институциональных и процедурных механизмов фискальной отчетности (как это было в предшествующем кодексе 2007 г.), сколько на ее качестве и надежности.

В первую очередь, рассматривается охват институтов в соответствии с которым бюджетно-налоговые отчеты должны консолидировать весь перечень организаций центрального правительства и предоставлять отчеты по каждой отрасли, оценивать качество самой фискальной отчетности как наиболее объективной основы для оценки уровня фактической прозрачности.

С этой целью пересмотренный Кодекс строится на трех ключевых аспектах раскрытия бюджетной информации: 1) бюджетно-налоговой отчетности; 2) прогнозировании и составлении бюджета;
3) анализе и управлении бюджетными рисками [3]. При этом учитываются по отдельности следующие параметры раскрытия бюджетной информации:

- $\quad$ охват учреждений государственного сектора, охват запасов и потоков;

- периодичность и своевременность представления отчетности;

- $\quad$ качество, доступность и сопоставимость бюджетной отчетности;

- $\quad$ надежность и достоверность представляемых бюджетных данных.

Рассмотрим ключевые аспекты Кодекса-2014, применительно к повышению открытости и прозрачности управления общественными финансами в Российской Федерации.

В первую очередь, считаем целесообразным обратить внимание на раздел 1.1 «Охват» при котором бюджетно-налоговые отчеты должны обеспечивать комплексный обзор бюджетно-налоговой деятельности государственного сектора и его отраслей в соответствии с международными стандартами.

Кодекс-2014 предлагает рассматривать отчеты организаций в соответствии со Статистикой государственных финансов МВФ (далее по тексту - СГФ). Применяемая до недавнего времени 
Административное и муниципальное право 6 (90) • 2015

\begin{tabular}{|c|c|c|c|c|}
\hline $\begin{array}{c}\text { Сектор } \\
\text { государственного } \\
\text { управления } \\
\end{array}$ & $\begin{array}{c}\text { Сектор } \\
\text { нефинансовых } \\
\text { корпораций } \\
\end{array}$ & $\begin{array}{c}\text { Сектор } \\
\text { финансовых } \\
\text { корпораций } \\
\end{array}$ & $\begin{array}{c}\text { Сектор } \\
\text { домашних } \\
\text { хозяйств } \\
\end{array}$ & $\begin{array}{c}\text { Сектор некоммерческих } \\
\text { организаций, обслуживающих } \\
\text { домашние хозяйства } \\
\end{array}$ \\
\hline \multirow{2}{*}{ Государственный } & Государственный & Государственный & \multirow{2}{*}{ Частный } & \multirow{2}{*}{ Частный } \\
\hline & Частный & Частный & & \\
\hline
\end{tabular}

Рисунок 1. Государственный сектор и его связь с другими институциональными секторам экономики[8].

СГФ-2001 в сектор государственного управления включала все государственные единицы и все нерыночные некоммерческие организации (НКО), контролируемые и в основном финансируемые государственными единицами. Нерыночные НКО с правовой точки зрения являются негосударственными структурами [4], однако считается, что они проводят государственную политику и фактически являются частью органов государственного управления. Нерыночными институциональные единицы, которые предоставляют товары и услуги домашним хозяйствам или обществу в целом в основном бесплатно или по ценам, не являющимся экономически значимыми (государственные вузы, школы, музеи, поликлиники и др.).

Вместе с тем, СГФ отмечает, что метод отнесения НКО к секторам должен быть идентичным методу, используемому в национальных счетах (CHC).

СНС также предлагает включить в сектор государственного управления центральные, региональные или местные органы государственного управления, фонды социального обеспечения и нерыночные некоммерческие организации, контролируемые государством. В сектор не включены государственные корпорации, даже если весь акционерный капитал таких корпораций принадлежит органам государственного управления. Сектор не включает квазикорпорации, которые являются собственностью органов государственного управления и контролируются ими. Вместе с тем, некорпоративные предприятия, принадлежащие государственным единицам, должны быть включены в сектор государственного управления [5].

Однако в обновленной версии СГФ-2013 содержится статистика по государственному сектору, который шире, чем сектор государственного управления и включает государственные финансовые (ЦБ, НПФ, ОВС, Микрофинансовые организации и др.) нефинансовые (частные клиники, больницы, школы, колледжи, университеты, научно-исследовательские организации др.) корпорации (рис 1).

Подразумевается, что государственные организации как финансовые, так и нефинансовые, - могут участвовать в проведении государствен- ной финансовой политики [6]. То есть для обеспечения открытости и прозрачности управления общественными финансами необходимо обладать информацией не только об институциональных единицах сектора государственного управления, но и государственных корпорациях, квазикорпорациях (не зарегистрированных как корпорации, но функционирующие так, как если бы они были корпорациями) [7]. На сегодняшний день в Российской Федерации не предоставляется информация по данным организациям и открывается информация только по сектору государственного управления.

Для предоставления информации о государственном секторе в целом необходимо пересмотреть ст. 152 Бюджетного кодекса Российской Федерации (далее по тексту - БК РФ) [9].

Судя по положениям ст. 6 БК РФ, среди участников бюджетного процесса, являющихся получателями бюджетных средств, нет организаций, относящихся к сектору финансовых корпораций и сектору нефинансовых корпораций. В связи с этим, можно констатировать, что требования Кодекса-2014 не коррелируют с положениями БК РФ.

Для устранения выявленного несоответствия, ст. 6 БК РФ в части получателей бюджетных средств следует изложить в следующей редакции: получатель бюджетных средств (получатель средств соответствующего бюджета) - государственный (муниципальный) орган, иная организация, находящееся в ведении главного распорядителя (распорядителя) бюджетных средств казенное учреждение, имеющие право на принятие и (или) исполнение бюджетных обязательств от имени публично-правового образования за счет средств соответствующего бюджета, если иное не установлено БК РФ (проект БК).

Второй критерий раскрытия информации - периодичность и своевременность представления отчетности - близок по содержанию к требованиям Оптимальной практики по обеспечению прозрачности бюджета ОЭСР. При анализе соответствия нормативной правовой документации и законодательной базы в Российской Федерации по критерию «периодичность и своевременность раскрытия информации» международным докумен- 
там (Кодексу-2014 и Оптимальной практике ОЭСР), были выявлены следующие аспекты:

1. Предварительный бюджетный документ (проект федерального бюджета) в Российской Федерации составляется в соответствии с гл. 20 БК РФ «Основы составления проектов бюджетов» [9] и Постановлением Правительства Российской Федерации №1010 «0 составлении проекта федерального бюджета и бюджетов государственных внебюджетных фондов Российской Федерации на очередной финансовый год и плановый период» [10].

2. Ежемесячные отчеты о поступивших доходах и осуществленных расходах предоставляются в соответствии с Приказом Минфина России от 28.12.2010 №191н (ред. от 19.12.2014) «Об утверждении Инструкции о порядке составления и представления годовой, квартальной и месячной отчетности об исполнении бюджетов бюджетной системы Российской Федерации» [11], публикуются в течение 30 дней и доступны на едином портале бюджетной системы, однако не сопровождаются пояснениями, требуемыми Оптимальной практикой. Существенные расхождения между фактическими и прогнозируемыми данными, наблюдаемые по многим направлениям расходования бюджетных средств, также не содержат пояснений.

3. Полугодовой отчет составляется, но не публикуется и не содержит обновленные сведения об исполнении бюджета, обновленный прогноз результатов исполнения бюджета на текущий и последующие годы. Исследование экономических допущений, лежащих в основе бюджета и их влияние не раскрывается (рекомендации к публикации Полугодового отчета в отношении Российской Федерации были сформулированы при оценке Индекса Открытости Бюджета (Open Budget Index) Международным бюджетным партнерством).

4. Годовые отчеты в соответствии с Приказом Минфина России от 28.12.2010 №191н (ред. от 19.12.2014) «Об утверждении Инструкции о порядке составления и представления годовой, квартальной и месячной отчетности об исполнении бюджетов бюджетной системы Российской Федерации» публикуются в течение 5 месяцев после окончания финансового гада, однако не содержат информацию об эффективности [11], в том числе с учетом сравнения показателей эффективности и фактически достигнутых результатов (рекомендации к по- вышении степени полноты «Проекта бюджета исполнительной власти» и «Годового отчета» в отношении Российской Федерации сформулированы при оценке Индекса Открытости Бюджета (Open Budget Index) Международным бюджетным партнерством).

5. Предвыборный отчет, составляемый непосредственно перед выборами и способствующий повышению информированности избирателей в Российской Федерации не представляется.

6. Долгосрочный отчет, предназначенный для оценки долгосрочной устойчивости текущей государственной политики, необходимый к опубликованию не реже одного раза в пять месяцев - не составляется.

При этом отчеты о кассовом исполнении бюджета в течение года и бюджетная статистика в течение года составляются с высокой степенью периодичности и своевременности. Отчеты о кассовом исполнении бюджета составляются ежемесячно и публикуются в течение 30 дней после окончания каждого месяца. Квартальные отчеты поступают в 35-дневныи срок после окончания квартала.

В соответствии с Бюджетным кодексом, Россия составляет два комплекта годовой отчетности, охватывающей все единицы сектора государственного управления в национальном определении. Вопервых, публикуется годовой отчет об исполнении бюджета на кассовой основе, в котором указываются государственные доходы, расходы и финансирование за предыдущий год. Во-вторых, публикуется финансовая отчетность по методу начисления, в которой приводятся отчеты о прибылях и убытках, балансы активов и пассивов и отчеты о потоках кассовых средств за предыдущий год. Оба отчета публикуются в течение пяти месяцев по окончании года [12].

Следующий критерий раскрытия бюджетной информации - качество, доступность и сопоставимость бюджетной отчетности.

«Доступность» заложена в принципе прозрачности бюджетной системы Российской Федерации ст. 36 БК РФ и включает доступность информации о ходе исполнения бюджетов, а также иных сведении о бюджетах по решению законодательных (представительных) органов государственной власти, представительных органов муниципальных образовании. Также доступность информации для общественности, открытость бюджетных процессов реализуются благодаря исполнению пункта 9 раздела II Бюджетного послания Президента РФ о бюджетной политике в 2014-2016 г. [13], Концепции создания и развития государственной интегрированной 
информационной системы управления общественными финансами «Электронный бюджет», Концепции открытости федеральных органов исполнительной власти, Приказа Минфина России №86-н, Министерства регионального развития Российской Федерации №357 и Министерства экономического развития №468 от 22 августа 2013 г. [14].

В Подпрограмме №3 «Обеспечение открытости и прозрачности управления общественными финансами» Государственной программы «Управление государственными финансами и регулирование финансовых рынков» (далее по тексту Подпрограмма №3, Подпрограмма) в соответствии с данным принципом сформулированы задачи 1 и 3 , а также направления реализации мероприятий 3.1 и 3.2. [15].

Обеспечение публичности процесса управления общественными финансами также заложено в Программе повышения эффективности управления общественными (государственными и муниципальными) финансами на период до 2018 года, одной из основных целей которой является повышение открытости и прозрачности управления общественными финансами (Программа). Программа утвержденная Правительством Российской Федерации 30.12.2013, устанавливает необходимость организации деятельности по участию граждан в бюджетном процессе в рамках системы раскрытия информации; развития Единого портала бюджетной системы; регулярной публикации «бюджета для граждан»; повышения бюджетной грамотности населения; участия в международных обзорах и проектах по открытости и прозрачности управления общественными финансами [16].

Обеспечение качества и осуществление независимой проверки налогово-бюджетной информации, реализуется в соответствии со ст. 2 №41-ФЗ от 05.04.2013 «0 Счетной палате Российской Федерации» [17], №212-ФЗ от 21.07.2014 «Об основах общественного контроля в Российской Федерации» [18], задачей 5 Подпрограммы №3 [15].

Следующий критерий раскрытия бюджетной информации: надежность и достоверность представляемых бюджетных данных.

По оценкам МВФ Годовая отчетность соответствует национальным стандартам бухгалтерского учета и ее надежность подтверждается Счетной палатой. Россия применяет национальный стандарт учета по методу начисления для всех государственных структур начиная с 2006 года. Аудиторский отчет Счетной палаты обычно включает ряд рекомендаций относительно совершенствования структуры и формы отчетов на основе данного стандарта.
Оценка прозрачности в налогово-бюджетной сфере в Российской Федерации в соответствии с Кодексом-2014 МВФ, была проведена группой сотрудников МВФ, которая выявила некоторые, подлежащие устранению недостатки. Среди рекомендаций МВФ отмечается необходимость [12]:

а) пояснения границ между сектором государственного управления, государственного и частного сектора и распространения институционального охвата бюджетной отчетности на государственный секторов в целом;

b) усиления сопоставимости бюджетов, статистики и отчетности в части отражения безналичных потоков и стоимостной оценки основных фондов;

c) увеличения объема раскрытия информации недополученных доходах из-за налоговых расходов (по оценкам МВФ бюджет потерял 1-2\% ВВП в годовом доходе в связи с налоговыми льготами. У органов управления нет официальной методики расчета налоговых расходов);

d) расширения охвата и углубления детализации годового бюджета;

е) усиления независимой проверки и повышения прозрачности официальных макроэкономических и бюджетных прогнозов;

f) расширения раскрытия информации о бюджетных рисках и усовершенствования их анализа;

g) регулярной публикации долгосрочных бюджетных прогнозов, не менее чем на тридцать лет;

h) усиления финансового надзора за контролируемыми государством предприятиями. Организации с государственным участием остаются за пределами отчетности. Государственные корпорации с расходами $28 \%$ ВВП не учтены в консолидированных бюджетно-налоговых отчетах.

Согласно положениям Кодекса-2014 организации, полностью или частично принадлежащие государству, должны предоставлять четкие ожидания относительно того, как будут определяться перечисления прибыли или выплаты дивидендов органам государственного управления. Годовой отчет организаций с участием государства должен содержать сведения о совокупной прибыли, нераспределенной прибыли и направлениях использования прибыли, а также о сумме средств, перечисленных в бюджет, и эта информация, исходя из международных требований, также должна включаться в годовую бюджетную документацию. Положения, регламентирующие данную процедуру до настоящего времени не учтены в российском законодательстве. 
Помимо общих принципов открытости бюджетных процессов, Кодекс-2014 содержит принципы бюджетно-налогового прогнозирования, бюджетного процесса и бюджетных.

Таким образом, можно утверждать, что законодательство Российской Федерации содержит достаточно большое количество норм, обеспечивающих открытость и прозрачность управления общественными финансами. Пере- чень рассмотренных документов не является исчерпывающим. Все рассмотренные выше и другие законодательные и нормативные правовые акты федерального уровня определяют только отдельные стороны процесса открытости и прозрачности управления общественными финансами. Значительное количество документов разработано в субъектах Российской Федерации и муниципальных образованиях.

\section{Библиография:}

1. http://skachate.ru/ekonomika/69443/index.html

2. IMF POLICY PAPER, UPDATE ON THE FISCAL TRANSPARENCY INITIATIVE, August 7, 2014

3. МВФ: Новые кодекс и оценка прозрачности в бюджетно-налоговой сфере. Доклад Р. Хьюз, Москва,2014.

4. Руководство по статистике государственных финансов 2001. http://www.imf.org/external/pubs/ft/gfs/manual/ rus/pdf/allr.pdf.

5. CHC 2008 .

6. http://www.minfin.gov.by/upload/jurnal/2013/2013_8_18.pdf.

7. http://www.tffs.org/pdf/method/2013/russian/psdsr.pdf.

8. Статистика долга государственного сектора. Руководство для составителей и пользователей // МВФ, 2014.

9. Бюджетный кодекс Российской Федерации.

10. Постановление Правительства Российской Федерации №1010 «0 составлении проекта федерального бюджета и бюджетов государственных внебюджетных фондов Российской Федерации на очередной финансовый год и плановый период».

11. Приказ Минфина России от 28.12.2010 №191н (ред. от 19.12.2014) «Об утверждении Инструкции о порядке составления и представления годовой, квартальной и месячной отчетности об исполнении бюджетов бюджетной системы Российской Федерации».

12. Российская Федерация. Оценка прозрачности в налогово-бюджетной сфере. МВФ, 2014.

13. Бюджетное послание Президента РФ о бюджетной политике в 2014-2016 г.

14. Приказ Минфина России №86-н, Министерства регионального развития Российской Федерации №357 и Министерства экономического развития №468 от 22 августа 2013 г.

15. Государственная программа «Управление государственными финансами и регулирование финансовых рынков».

16. Программа повышения эффективности управления общественными (государственными и муниципальными) финансами на период до 2018 года.

17. №41-ФЗ от 05.04.2013 «0 Счетной палате Российской Федерации».

18. №212-ФЗ от 21.07.2014 «Об основах общественного контроля в Российской Федерации».

\section{References (transliterated):}

1. http://skachate.ru/ekonomika/69443/index.html

2. IMF POLICY PAPER, UPDATE ON THE FISCAL TRANSPARENCY INITIATIVE, August 7, 2014

3. MVF: Novye kodeks i otsenka prozrachnosti v byudzhetno-nalogovoi sfere. Doklad R. Kh'yuz, Moskva,2014.

4. Rukovodstvo po statistike gosudarstvennykh finansov 2001. http://www.imf.org/external/pubs/ft/gfs/manual/rus/ pdf/allr.pdf.

5. $\quad$ SNS 2008.

6. http://www.minfin.gov.by/upload/jurnal/2013/2013_8_18.pdf.

7. http://www.tffs.org/pdf/method/2013/russian/psdsr.pdf.

8. Statistika dolga gosudarstvennogo sektora. Rukovodstvo dlya sostavitelei i pol'zovatelei // MVF, 2014.

9. Byudzhetnyi kodeks Rossiiskoi Federatsii.

10. Postanovlenie Pravitel'stva Rossiiskoi Federatsii №1010 «0 sostavlenii proekta federal'nogo byudzheta i byudzhetov gosudarstvennykh vnebyudzhetnykh fondov Rossiiskoi Federatsii na ocherednoi finansovyi god i planovyi period».

11. Prikaz Minfina Rossii ot 28.12.2010 №191n (red. ot 19.12.2014) «Ob utverzhdenii Instruktsii o poryadke sostavleniya i predstavleniya godovoi, kvartal'noi i mesyachnoi otchetnosti ob ispolnenii byudzhetov byudzhetnoi sistemy Rossiiskoi Federatsii».

12. Rossiiskaya Federatsiya. Otsenka prozrachnosti v nalogovo-byudzhetnoi sfere. MVF, 2014.

13. Byudzhetnoe poslanie Prezidenta RF o byudzhetnoi politike v 2014-2016 g.

14. Prikaz Minfina Rossii №86-n, Ministerstva regional'nogo razvitiya Rossiiskoi Federatsii №357 i Ministerstva ekonomicheskogo razvitiya №468 ot 22 avgusta 2013 g.

15. Gosudarstvennaya programma «Upravlenie gosudarstvennymi finansami i regulirovanie finansovykh rynkov».

16. Programma povysheniya effektivnosti upravleniya obshchestvennymi (gosudarstvennymi i munitsipal'nymi) finansami na period do 2018 goda.

17. №41-FZ ot 05.04.2013 «0 Schetnoi palate Rossiiskoi Federatsii».

18. №212-FZ ot 21.07.2014 «Ob osnovakh obshchestvennogo kontrolya v Rossiiskoi Federatsii». 